\title{
Evaluation of a school-based physical activity programme aimed at reducing childhood obesity and improving cardiovascular risk profile in 8-9-year-old Northern Irish schoolchildren
}

\author{
A. M. Gallagher ${ }^{1}$, L. C. Breslin ${ }^{1}$, T. Bradley ${ }^{2}$, L. Allen ${ }^{2}$, C. M. Craig ${ }^{1}$, M. P. Bonham ${ }^{1}$ \\ and T. A. McCrorie ${ }^{1}$ \\ ${ }^{1}$ School of Biomedical Sciences, University of Ulster, Coleraine BT52 1SA, UK and ${ }^{2}$ Sports Development, \\ Derry City Council, Strand Road, Derry BT48 7NN, UK
}

Primary school is an ideal setting to implement programmes aimed at influencing health behaviours in young children and thereby modulate health outcomes in later life. However, to date, school-based programmes have often shown no effects because of limited duration, lack of multidimensional approach and/or proper evaluation ${ }^{(1)}$. The 'Fit Futures in Schools Programme', developed by Derry City Council, is targeted at P5 children (8-9-year-olds) attending schools located in areas of high social deprivation. The programme is delivered in schools on a weekly basis and involves 15 min education based on a health theme followed by $1 \mathrm{~h}$ physical activity that supports the theme. The aim of the present study was to evaluate the impact of this programme on body composition, fitness and health behaviours.

Between 2006 and 2008 a total of 349 children (mean age 8.1 years) participated in the study and were randomly assigned, on a class basis, to the control or intervention group. At any given time within a given school one P5 class received usual curriculum (control group) and one P5 class received the programme for $\geq 20$ weeks (intervention group). Data collected included anthropometry (height, weight, waist circumference) and measures of fitness (cardio-respiratory fitness (CRF) using a standardised 20 m multi-shuttle test; flexibility (flex) using a sit-and-reach test and grip strength by grip dynamometer). A subsample of children ( $n 23$ control, $n 29$ intervention) also completed a $4 \mathrm{~d}$ food diary, concurrent with objective measurement of physical activity levels (tri-axial accelerometry) and only those with $>600 \mathrm{~min} / \mathrm{d}$ and $>2 \mathrm{~d}$ of recordings were included in the analysis. High levels of overweight and obese children $(15.8 \%$ boys; $23.6 \%$ girls) were observed using International Obesity Taskforce cut-offs for BMI ${ }^{(2)}$. At baseline boys had higher $\mathrm{CRF}$ than girls $(P=0.002)$ whereas girls had higher levels of flex than boys $(P<0.001)$, but there were no gender differences for grip strength. Over time body composition (all measures) did not change in either group. Over time CRF in both boys and girls in the intervention group increased to a greater extent when compared with the control group $(P<0.001)$.

\begin{tabular}{|c|c|c|c|c|c|c|c|c|c|c|c|c|c|}
\hline & \multicolumn{6}{|c|}{ Control group } & \multicolumn{6}{|c|}{ Intervention group } & \multirow[b]{3}{*}{$P \dagger$} \\
\hline & \multicolumn{2}{|c|}{ Baseline } & \multicolumn{2}{|c|}{ Final } & \multicolumn{2}{|c|}{$\Delta^{+}$} & \multicolumn{2}{|c|}{ Baseline } & \multicolumn{2}{|c|}{ Final } & \multicolumn{2}{|c|}{$\Delta^{+}$} & \\
\hline & Median & IQR & Median & IQR & Median & IQR & Median & IQR & Median & IQR & Median & IQR & \\
\hline Boys & & & & 81 & & & & & & 79 & & & \\
\hline CRF (laps) & 11 & $8-16$ & $13 * * *$ & $9-20$ & 1 & $-2-7$ & 10 & $9-15$ & $17 * * *$ & $12-25$ & 7 & $2-14$ & $<0.001$ \\
\hline Flex $(\mathrm{cm})$ & 17 & $10-24$ & $11 * * *$ & $5-14$ & -5 & -15 to -1 & 16 & $9-22$ & $12 * * *$ & $8-16$ & -2 & -10 to -2 & 0.016 \\
\hline Girls & & & & 78 & & & & & & 64 & & & \\
\hline CRF (laps) & 9 & $8-10$ & $9 * * *$ & $8-12$ & 0 & $-2-4$ & 9 & $7-10$ & $12 * * *$ & $9-18$ & 4 & $0-8$ & $<0.001$ \\
\hline Flex $(\mathrm{cm})$ & 20 & $13-29$ & $14 * * *$ & $8-18$ & -4 & $-15-0$ & 21 & $16-28$ & $17 * * *$ & $12-19$ & -4 & $-17-1$ & 0.836 \\
\hline
\end{tabular}

IQR, interquartile range; $\Delta^{+}$, change over time (final minus baseline). Values were significantly different from those at baseline (Wilcoxon signed ranks test): $* * * P<0.001$.

$\dagger$ Change over time for control $v$. intervention (Mann-Whitney $\mathrm{U}$ test).

Accelerometry ( $n 15$ control, $n 15$ intervention) showed that over time physical activity increased only in the intervention group $(P=0.028)$ and the magnitude of this change was significantly greater for the intervention group (mean 1362 (SE 562) vector magnitude $(\mathrm{VM}) / \mathrm{d})$ compared with the control group (mean $-186(\mathrm{SE} 213) \mathrm{VM} / \mathrm{d} ; P=0.018)$. Absolute energy intakes $(\mathrm{kJ} / \mathrm{d}) \mathrm{decreased}$ over time for intervention $(P=0.019)$ but when the magnitude of change was considered and compared with that of the control group this result did not reach significance. It appears that this relatively-short intervention programme can increase the fitness of children and may be positively impacting on health behaviour (i.e. increasing total physical activity). Whether these effects are sustained beyond the intervention period is currently being considered.

This work was supported by a research grant from Northern Ireland Chest Heart and Stroke.

1. Brown T \& Summerbell C (2009) Obes Rev 10, 110-141.

2. Cole TJ, Bellizzi MC, Flegal KM et al. (2000) Br Med J 320, 1240-1243. 